\title{
PARTICULARITIES OF THE HEARING TACTICS IN THE CASE OF PERSONS WITH DISABILITIES
}

\author{
Gh. Popa, G. Țîru
}

\section{Gheorghe Popa}

Romanian-American University, Bucharest, Romania

*Correspondence: Gheorghe Popa, 1B Expozitiei Blv., Sector 1, 012101, Bucharest, Romania

E-mail: popa_gheorghe1959@yahoo.com

\section{Gabriel Țîru}

Psychology Expert, Romania

Email: tiru.gabriel@gmail.com

\section{Abstract}

This paper attempts to polarize the attention of the judicial authorities of the Romanian State on the complex issues raised by the hearing of persons with special needs from two perspectives, that of compliance with the criminal procedural framework and that of the observance of human rights. It also aims to provide practical solutions that might facilitate communication with such persons depending on their type of disability and solve the problem of accessibility in the investigator-citizen relationship. Modern approaches in the specialized literature grant an increasingly wider space to knowing the accused or the defendant's personality, adapting the investigator's speech to this reference point and individualizing the ways of relating throughout the judicial investigation. Moreover, a specific pattern of the personality of the criminal investigation body is outlined, through the psychointellectual and moral-affective qualities of the person leading the investigation that might ensure the success of this judicial approach specific to the hearing of people with special needs.

Keywords: deficiency, handicap, disability, special needs, accessibility, hearing, communication strategies.

\section{Introduction}

When considering the behaviour and attitude of a representative of public authority in relation to a person with special needs, particular attention is required, which derives from a double perspective, referring to the concept of interpersonal relationship, as well as to the expectations that society has of an institutionally-employed person. The violation of the first concept is contrary to morality and subject to internal censorship and the violation of the second concept clashes with deontological norms and with the entire national and international law. Consequently, we have an intrinsic perspective of one's self-image and an extrinsic one of the institution's image, both being equally important in the short term as well as the long term, and damage to either should be carefully avoided.

\section{The Hearing Tactics in the Case of Persons with Disabilities - General Rules}

In support of the legal action taken to find out the truth, the criminal investigation bodies must know, address and use appropriate methods and patterns of behaviour in relation to a disabled person. While there are clear and precise rules in approaching the legal side of the criminal investigation, their formal and informal application requires a particular approach that takes into account the very particularity of the subject of these legal proceedings, the person with special needs, with disabilities. The particularities of the approach will be dictated by the categories of handicap (profound, severe, moderate and mild) and the dysfunctions 
associated with each category. The categories we take as the basis of the situational analysis carried out in this chapter will be disabilities of the following types: physical, somatic, verbal, auditory, visual, associated, deaf-blindness and other rare diseases.

To identify the real needs and the complex problems raised by the hearing of these people we have initiated a scientific research in Romanian prisons. The lot undergoing the research was selected from five prisons, in compliance with the pre-existing methodology in the Romanian penitentiary system and the research was done with the written consent of the sentenced persons to participate in this study, their acceptance being built around the concept of personal data protection.

This study was conducted on a sample of 53 male subjects of different ages, with varying degrees of handicap, convicts with final sentences for various offences. The legal classification of the antisocial acts that they committed involves imprisonment sentences, within a range between three years' imprisonment and life imprisonment. The types of crimes considered relevant in the research are: murder, wounds and blows causing death, robbery, theft, road traffic offences, fraud, destruction, sexual offences, drug trafficking and consumption, human trafficking and begging. The study group comprises people who repeatedly committed antisocial acts, as well as first offenders (non-repeat offenders).

The data obtained were used in drawing up tactical rules useful to the investigator and covering the area of three essential concepts of judicial proceedings, namely tactical rules, communication and relating with these categories of persons with special needs.

Interviewing the accused or the defendant is an obligation of the criminal investigation body, as well as of the court.

Access and Accessibility - A first aspect that we need to consider when organizing the interrogation of a disabled person is access and current facilities which naturally pose no problem to people with normal health status. The initial barrier that most people with disabilities have to face is that of the physical access to the place where the judicial activity is carried out. For many of them, the lack of access to the parking lot, to the building, is a problem, therefore we need to find answers to questions such as: Is there an available parking space?; Is there enough space to get in/out of the car?; Can these persons get into the building?; Is access done through an entrance provided with a special slope?; Is there a lift (elevator); Can they move and/or rotate through the corridors of the building?; Are there any locked or self-locking doors on the route?; Is there any place of rest or pause?; Is there easy access to the means of current hygiene/sanitary facilities?; Is there a nearby doctor or medical office, in case of necessity?, etc. Some people with physical disabilities cannot perform the same physical activities as othes. This includes people with walking difficulties or those with abnormal physical dimensions. These people may use wheelchairs, canes and other assistive devices. Those whose arms or hands are affected may have difficulties in opening doors or access ways, in writing by using standard tools (fountain pen, ballpoint pen), etc. Some people with motor disabilities may quickly tire or undergo severe pain, therefore requiring breaks, so it is desirable that the interrogation should take place in a space on the ground floor or with easy access.

The criminal investigation and prosecution bodies should be aware of the physiological and mental limitations of people with disabilities, in order to be able to accurately understand and interpret the facts described, presented by these people during the hearings, regardless of their legal capacity (witness, victim or suspect).

In all specialized bibliography we find formulations already established stating that the hearing is the procedural act by which individuals, the accused or the defendant, the other parties/witnesses expected to hold data in connection with the offence or the offender, or who may provide information for the establishment of the state of facts are called to submit them or provide explanations before the criminal judicial bodies. The first logical conclusion is that the hearing is based on the communication of cognitive experience transmitted through language. 
Communication is essentially an outward manifestation of an inner reality, while also being relation, information, action and transaction. Taking into account the fact that the actual hearing/interrogation is based on communication and inter-relationship and that the accurate interpretation of the facts depends on its success, we further bring to your attention a number of rules that the criminal investigation body must consider in the presence of a disabled person $^{1}$. In the specialized literature, T. Bogdan identifies a few tactical rules ${ }^{2}$ that can help establish a verbal contact between interlocutors, but in our particular case what matters is to identify the communication mode first and only then the actual transmission of the informational content, which in the case of a hearing is done through the question-answer technique. Thus, the following tactical rules are to be remembered:

1. In your contact with the interlocutor remember that before being listened to, we are looked at (except by persons with severe sight disabilities);

2. Determine whether the person you are hearing has communication difficulties and whether he/she is classified as a person with a handicap. If so, check the degree of handicap (mild, moderate, severe or profound) and the functional limitations corresponding to each degree;

3. Determine whether you need an interpreter or not;

4. Identify a suitable system of communication, depending on the type of disability and the most severe impairment interfering with the communication process;

5. Identify the specific mode of communication (verbal, sign language, combined);

6. Expressing yourself as clearly as possible, in an understandable language, accessible to the interlocutor, is mandatory. The vast majority of people with special needs prefer the communication mode that uses recordings, most commonly using large size characters, Braille/Moon characters, digital records, e-mails, existing texts or combinations thereof;

7. If the person in question considers speaking in public as difficult and as emphasizing his/her deficiency (disability), it would be preferable to provide a more intimate setting or a setting with a limited number of participants;

8. Listen carefully to what the person is saying or transmitting, always answer questions related to the ambient factors or the atmosphere of the discussion itself and do not be misled by the way the utterances are pronounced;

9. Ensure continuity of the hearing/interrogation and conduct discussions so as to avoid being unduly interrupted by other people or activities. Remember that people with special needs get tired more easily and are generally more sensitive to prolonged actions;

10. Do not forget to check whether during the hearing the person should administer themselves or be administered some treatment. Check the psycho-physiological implications of this type of treatment.

Organizing/planning the hearings - In planning the activities, one must take into account the degree and type of handicap, so that the activity can be carried out, and adapting the investigation plan to the situational reality is necessary. As a personal opinion, it is recommended that the activity should not be planned for a date and time when medical activities are scheduled (surgical operations, treatments, regular mandatory or exploratory analyses, etc.) and the investigator should be informed about the person's medical status on the day of the interrogation in order to make sure that no new problems or

\footnotetext{
${ }^{1}$ Înțelegerea dizabilității - Ghid de bune practici (Understanding Disability - a Good Practice Guide) / ETTAD 134653-UK-GRUNDTVIG-GMP (pp. 13-14).

2 Tiberiu Bogdan, Ion Sîntea, Rodica Drăgan Cornianu, Comportamentul uman în procesul judiciar (Human Behaviour in the Judicial Process), Ed. MI (Ministry of the Interior Publishing House), pp. 151-152, personal processing and interpretations.
} 
complications/aggravations of existing ones should occur. Going further down to mediumlevel details, one should first check the conditions of accessibility, the possibility to provide medical support if needed, to provide a space that might guarantee a minimum of privacy in case self-administration of treatment is needed, access to meeting one's physiological needs, technical equipment and infrastructure that would ensure communication depending on the type of handicap and recordings, defining the participants and their roles. All these should be set out in detail, not only in general terms. Already in the planning stage, the investigator will make sure that they understand the correct meaning of the physical, psychological and physiological limitations corresponding to the degree and type of handicap of the person they will be hearing and that they are aware of the appropriate relationship and communication strategies.

Formulating hypotheses - In the case of persons with special needs, our view is that the interpretation of the data derived from the evidentiary material available does not bear discussion, but the formulation of hypotheses might raise some comments in the sense that more elaborate versions will have to take into account any mobility or time-space orientation limitations on the part of the suspect. In other words, they must be very realistic in terms of the real possibilities for action and for the actual materialization of the criminal act, in relation to the type of handicap, configuration of the space/land, the presence/absence of natural barriers and the possibility to overcome them (or the lack thereof), interaction with the victim (the ability to fight back), use of a weapon or physical force, motive, etc. From this we can deduce whether it was possible for the respective person to commit the offence or not, whether there was only one offender or he/she had been helped by someone else and, not least, analyze the possibility for that person to have been intentionally placed in the position of sole author. I have mentioned here examples of the situational plans that I considered as relevant, they are actually much more diversified depending on the concrete situation. All these will be correlated with data obtained from investigations of the crime scene, statements, expertises, etc., and will provide a note of veracity or discrepancy. The latter variant will require a reanalysis and reformulation of the hypothetical work-in-progress versions.

Providing an interpreter is required by law on the basis of the general assumption that the presence of an interpreter is necessary when the accused or the defendant to be heard does not understand Romanian or, even if they do understand it, they cannot express themselves in it. For persons with communication disabilities (of speech and hearing), the reason for the need to provide an interpreter is basically the same, not understanding (the) "language" or being unable "to express oneself" in it, but here it is not a different language that one doesn't know, belonging to a different cultural space or a dialect, but rather the inability to articulate speech sounds as they are recognized in everyday oral communication.

\section{TACTICAL RULES OF HEARING DISABLED PERSONS, CONSIDERING THEIR HANDICAP}

The hearing of the accused or defendant is performed separately (Art. 71, para. 1). We should start by clarifying the specifics of procedural activities in relation to the issues of people with special needs ${ }^{3}$.

In the relationship with a disabled person using a mobility assistive device, the investigator or police officer should not, out of the desire to be helpful, push the wheelchair without first politely asking for permission. According to the ETTAD good practice guidelines, wheelchair users move independently anyway, and if they need help when encountering obstacles they will ask for help themselves. The investigator should not check the stability/safety of a person or touch their crutches, for example, without their consent. When interviewing a person in a wheelchair, the investigator will place himself at that

\footnotetext{
${ }^{3}$ See Ghidul practic de relaționare pentru anchetator raportat la persoanele cu nevoi speciale (An Investigator's Practical Guide to Relating to Persons with Special Needs).
} 
person's level and at a relatively close distance. However, the orthostatic (standing) position should be avoided, as this leads to a dominant position on the part of the investigator.

The person with language and speech difficulties - In such a situation, the investigator will display a calm demeanour and give the person more time to finish/complete what he/she has to say. There are people who appreciate the help in completing their sentences, but one must determine whether the person in question accepts it or whether such an intervention only further heightens the relational discomfort. The investigator can be put in the position of hearing a person with speech difficulties, such as stuttering. In general, the flow of speech is disrupted and this can cause discomfort both to the speaker and the listener. The cause for stuttering remains unknown. Latest research suggests that there is an innate predisposition for stuttering, which might be inherited, and then there are other factors that will influence when and how stuttering occurs and how it progresses. These factors can be broadly divided into four categories: physiological, linguistic, environmental and emotional (Rustin, Botterill and Kelman, 1996).

The person with visual impairment - Besides the general rules of conduct and access to the premises set out in the above paragraphs, upon the person's entry into the investigation room/office, if he/she has never been there before, the investigator will give a brief description of it (size, windows, door position and content: furniture, equipment, etc.). The investigator will introduce himself/herself, by clearly saying his/her last name, first name (rank, if applicable), will specify the location (police station, prosecutor's office, laboratory, etc.), will mention and indicate the presence of other people in the office (prosecutor, other investigators, psychologist, sociologist, forensic pathologist, etc.), as well as their role in the investigation. In group conversations, when referring to a particular person, the investigator will use their name, and if another participant on behalf of the authority intervenes in the debate on their own account, they should begin by introducing themselves. Some people have blurred vision or cannot accurately estimate distance and speed or they cannot discriminate between objects of similar colours or they can only see shadows. Before inviting the person to present what they know, you should provide clear instructions and explanations. It is possible for people with visual disabilities not to have experience in making structured presentations or coherent descriptions. If, for any reason, you must temporarily leave the investigation office, inform the person and do not let them speak in an empty room. Tell them that the conversation is over and that you are going to another office or that you are showing them out.

With visually-impaired people, upon presentation of written materials, the investigator will use large-sized characters. Characters (fonts) of sizes ranging from at least 16 to 18-20 (preferably) are recommended. This can be achieved by copying an enlarged version or by directly using large characters from the computer (printing should be preferred to photocopying). If the office is provided with multimedia facilities, a zoomed projection on screens or directly on a white wall can be a suitable alternative. Today's computer technology has the benefit of offering a great many solutions to such problems, such as the use of programs with dedicated facilities (e.g. Microsoft Windows has Accessibility Options) that allow for changes in resolution, colour and size, text and command verbalization. There are software products that enable voice recognition, an extremely useful facility, such as DragonDictate and ViaVoice in the case of Apple technology, which require minimal user training and practice. Speech checker "Texthelp" is also available.

If the presentation of video footage or photographic slides is required, the accused should be positioned so that he/she can hear/see well. The investigator will take measures to ensure optimal lighting, as apparently minor adjustments can make a big difference. The degree of accommodation varies from person to person, glare light posing, at times, as many problems as darkness. Emphasis will be put on choosing the appropriate degree of light by consulting the person interviewed. All these activities should not be considered as a waste of 
time because they provide fair trial guarantees and certainty about the relevance of the answers obtained.

There are people with special needs who come accompanied by a guide dog. There is a natural tendency for the investigator to focus on the task (obtaining investigation-related information, clarifzing defences, verifying hypotheses). Remember that a guide dog has needs and it is possible for the person interviewed to no longer focus on the accuracy of the statement, being more concerned about the dog's needs.

The person with hearing difficulties - It is quite common for people with hearing impairments to use hearing devices, even if they also use other forms of communication. These devices amplify sounds, but all sounds are amplified equally, therefore background noise may pose them real problems. It is recommended that the investigator should keep their head straight when speaking, because even if they don't state it, these people try supplementing information by "lip-reading". Also they should be careful not to have their mouth covered by their hand, cigarette and should not be chewing gum. For the same reasons it is recommended that the investigator should not have a beard or moustache.

The investigator should be positioned so that their face is sufficiently lit/visible and talk at a slower pace than they usually do so that the person interviewed can keep up with the discussion. Otherwise, there will be an information disparity, that might hinder good relations and generate misunderstandings, unsynchronized answers, confusing explanations or gaps in communication. If a sign language interpreter accompanies the deaf person to facilitate communication, the investigator will always be facing and addressing the person interviewed, not the interpreter. This does not exclude positioning himself/herself so that both the interpreter and the person interviewed can see him/her.

When the hearing involves a person with hearing difficulties, the investigator will make sure that the person is attentive and watches him/her, while he/she is asking the questions. To attract the attention of the person interviewed, some decent gestures or a light touch on the shoulder may be used. The investigator must not lose patience, nor forget that raising his/her voice does not help. He/she should help the person to overcome the inevitable barrier that the symbol of the authority creates, namely the prosecution service/police station. If there are several representatives of the authorities involved in the hearings, the investigator coordinating the activity will make sure that they take turns in the interrogation and that there is no disturbing background noise.

When questions are formulated and an interpreter is present, the interpreter should be given enough time to translate what is being discussed into sign language and the person with hearing difficulties should also be given the necessary time to answer. Unnecessary abstractions or very lofty language can alter communication. If the hearing/interview takes a long time, you should occasionally interrupt the activity to provide a short break for the interpreter, knowing that translation into sign language is a demanding task.

If there are several people in the office who are involved in the activity (prosecutor, police officers, psychologist, etc.), they should be asked in advance to indicate through visible gestures when they start talking and not to walk around the office while talking.

The deaf-blind person - In such a case, the investigator must not forget that people who are born with a condition of this type have poorly developed language or do not speak at all, because of their ear canal impairment, and, given their visual deficiency, they have no representation of objects, phenomena and events. Thus, it is necessary to establish a rational relationship that might provide trust and security, describe the space in which the hearing takes place and offer the actual possibility for the person to explore by touch the surrounding objects. Also, the message will be repeated at a slow pace in order to make it easier to understand.

The person with dyslexia - Some people with dyslexia are familiar with voice recognition software programs (e.g. Dragon Dictate or, for Mac - Via Voice, Texthelp). The Windows environment is also provided with specialized programs, which you can find in the 
Control Panel, the "Easy Access Center" window. The investigator will make sure that such software products are available on the computers in the office where the hearing is to be carried out and that he/she is familiar with how to use them. For fluency of the activities, it is also advisable to have an IT specialist present.

The person with an undeclared/unrecognized disability - It is the type of disability that we consider as the most insidious, because when the handicap is visible, as in the cases described above, on the one hand the investigator is aware of the existence of the condition and complies with the situation, and on the other hand the person has already internalized this condition. When the impairment is not visible and has no explicit expression, has an episodic occurrence or only occurs in certain situations with a high emotional load, the people in question do not see it as a disability and sometimes do not even say they have certain special needs. People with such conditions may consider themselves prejudiced if they reveal their problem.

Panic attacks, anxiety, phobias, seizures and epilepsy are the most common conditions in this category, the main problem being that they occur spontaneously. Being unpredictable, it is hard to solve them in a controlled manner, the spontaneity of their occurrence generating a spontaneity of reaction. The investigator must remain calm, collected and deal lucidly with such situations. We recall here the need for the investigator to be familiar with the characteristic symptoms and with the first measures recommended in such cases. As a prevention measure, the investigator should not show his/her discontent with these people's requests for frequent breaks, for example, to eat at certain times or to solve certain physiological needs. The investigator will facilitate, on request, the person's withdrawal into a private space for self-administration of medication, if there is no medical service available in the neighbourhood.

The stress resulting from the emergence of new situations, as is the case in a criminal investigation, may affect some people, for example those suffering from asthma. The physical environment may affect them, particularly certain factors, such as dust, cigarette smoke, strong air fresheners, which can trigger an asthma attack. People with these conditions usually take their medication with them, but they should be asked from the very beginning of the hearing whether they are under treatment. In parallel, the investigator will follow the physiological reactions of the person to be heard and, in case of a fit, will immediately call for emergency health care assistance.

Finally, we should also mention multiple handicap, which is a combination of two or more impairments in the same person, the two deficiencies being, as a rule, subsequent to each other. The most important and serious multiple handicaps are autism and deaf-blindness.

\section{Conclusions}

Generally, in the approach of the recommendations contained in this paper, we plead for an increased degree of attention in the establishment of the relationship between the criminal investigation and prosecution bodies and the people with special needs, in terms of the support provided to overcome the limitations that the disabilities corresponding to each type of handicap impose and to participate actively in a fair criminal trial. We must also stress that condescension and kindness, as main attributes of the relationship, should not mistakenly turn into a lenient or favouring attitude, only into a balanced and fair one. In order to support this approach, an "Investigator's Practical Guide to Relating to Persons with Special Needs" (Ghidul practic de relaționare pentru anchetator raportat la persoanele cu nevoi speciale) has been developed. The guide contains provisions applicable to the investigation and prosecution bodies, with tasks/responsibilities related to the hearing/interviewing of people with special needs.

\section{Bibliography}


*** Romanian Criminal Procedure Code of 01.07.2010, published in the Official Journal, Part I, no. 486 of 15.07.2010.

*** European Disability Strategy 2010-2020 - Communication from the Commission to the European Parliament, the Council, the European Economic and Social Committee and the Committee of the Regions - European Commission Brussels, 15.11.2010 COM (2010) 636 final. \{SEC (2010) 1323\} \{SEC (2010) 1324\}.

Understanding Disability - a Good Practice Guide / ETTAD - 134653-UKGRUNDTVIG-GMP.

Handbook of Prisoners with Special Needs, Criminal Justice Handbook Series, United Nations Office on Drugs and Crime - Vienna, United Nations Publication, New York, 2009.

A Guide to International Human Rights Instruments for Persons with Intellectual Disability, Inclusion Europe and Incluziune România (Inclusion Romania).

Ion Neagu, Tratat de procedură penală (A Treatise on Criminal Procedure), Universul Juridic Publishing House, 2008.

Tudorel Butoi, Psihologie judiciară - Tratat universitar (Legal Psychology - a University Treatise), Pinguin Book Publishing House, Bucharest, 2008.

Emilian Stancu, Procedee tactice folosite în investigațiile penale. Evoluții (Tactical Procedures Applied in Criminal Investigations. Evolutions), AIT Laboratories Publishing House, Bucharest, 2011.

Tiberiu Bogdan, Ion Sîntea, Rodica Drăgan Cornianu, Comportamentul uman în procesul judiciar (Human Behaviour in the Judicial Process), Ed. MI (Ministry of the Interior Publishing House), 1988.

http://www.anph.ro/info_pub.php?m=Informatii publice. 